\title{
Intensidade tecnológica e desempenho da indústria de transformação na Mesorregião Metropolitana de Curitiba (MMC)
}

\author{
Rogério Allon Duenhas* \\ Michelli Gonçalves Stumm** \\ Raquel Valença*** \\ Sidarta Ruthes**** \\ Marilia de Souza*****
}

Resumo: O artigo buscou analisar o desempenho da indústria da transformação na Mesorregião Metropolitana de Curitiba (MMC) por meio_de diversos indicadores e tendo em vista os níveis de intensidade tecnológica propostos pela Organização para Cooperação e Desenvolvimento Econômico (OCDE). Considerado o período de 2002 a 2011, verificou-se que tal mesorregião vem se concentrando e se especializando em atividades industriais intensivas em tecnologia.

Palavras-chave: Desempenho; Indústria de transformação; Intensidade tecnológica.

Classificação JEL: L60, O14, P48.

\footnotetext{
* Doutor em Desenvolvimento Econômico pela Universidade Federal do Paraná e pesquisador nos Observatórios Fiep/ Sesi/Senai/IE.

*** Mestre em Sociologia pela Universidade Federal do Paraná, pesquisadora nos Observatórios Fiep/Sesi/Senai/IEL.

*** Mestre em Organizações e Desenvolvimento pelo Centro Universitário FAE, pesquisadora nos Observatórios Fiep/ Sesi/Senai/IEL.

**** Doutorando em Tecnologia pela Universidade Tecnológica do Paraná, Coordenador dos Observatórios Fiep/Sesi/ Senai/IEL.

***** Doutora em Sciences Mécaniques pour l'Ingénieur pela Université de Technologie de Compiègne, Gerente dos Observatórios Fiep/Sesi/Senai/IEL.
} 


\section{Introdução}

A evolução da produtividade industrial, um dos fatores determinantes no grau de competitividade nacional e internacional, está associada, dentre outros elementos, ao uso de tecnologias. Nesse sentido, as mudanças de intensidade tecnológica no processo produtivo se mostram importantes no monitoramento e na avaliação do desenvolvimento industrial de um país e/ ou região.

O presente trabalho busca contribuir com esses aspectos ao avaliar o desempenho da indústria da transformação na Mesorregião Metropolitana de Curitiba (MMC) em relação às demais - do Paraná e do Brasil. Especificamente, buscou-se analisar tal indústria por meio de diferentes indicadores de desempenho, tendo em vista a metodologia da Organização para Cooperação e Desenvolvimento Econômico (OCDE) que classifica os setores industriais segundo níveis de intensidade tecnológica.

Assim, o estudo visa a trazer elementos para o melhor entendimento da dinâmica econômica presente na mesorregião e a auxiliar na formulação de políticas de desenvolvimento industrial, especialmente aquelas voltadas a incentivar inovações tecnológicas.

O trabalho está estruturado em três outras seções além desta introdutória. A subsequente apresenta a metodologia proposta pela OCDE e a base de dados utilizada. Na seguinte, por sua vez, são calculados e analisados diversos índices que representam a evolução do emprego relacionada à intensidade tecnológica na indústria de transformação da Mesorregião Metropolitana de Curitiba (MMC). Por fim, na última, são delineadas as principais conclusões e considerações finais.

A importância de conhecer a distribuição dos trabalhadores de acordo com a intensidade tecnológica decorre do fato de que as indústrias intensivas em tecnologias são mais inovadoras, utilizam recursos de forma mais eficiente, oferecem salários mais elevados e ainda se revelam mais bem-sucedidas em aumentar o market-share (Markwald, 2004). Furtado e Carvalho (2005) ressaltam que um setor intensivo em tecnologia garante especialização diferenciada às economias mais desenvolvidas e maior solidez à indústria local.

\section{Metodologia da OCDE e base de dados}

Para mensurar o nível de intensidade tecnológica da indústria da transformação em análise, utilizou-se a taxonomia proposta pela Organização para Cooperação e Desenvolvimento Econômico (OCDE), descrita no documento intitulado International Standard Industrial Classification of all Economic Activities (Isic), Rev. 3.1, Technology Intensity Definition, que padronizou e classificou as atividades econômicas industriais da seguinte maneira:

- Alta intensidade tecnológica: setores aeroespacial, farmacêutico, de informática, de eletrônica e telecomunicações, de instrumentos; 
- Média-alta intensidade tecnológica: setores de materiais elétricos, de veículos automotores, de química, ferroviário e de equipamentos de transporte, de máquinas e equipamentos;

- Média-baixa intensidade tecnológica: setores de construção naval, de borracha e plástico, de coque, de refinados de petróleo e combustível nuclear, de não metálicos, de metalurgia básica e metálicos;

- Baixa intensidade tecnológica: setores de reciclagem, de madeira, papel e celulose, editorial e gráfico, de alimentos, bebidas e fumo, de têxteis e confecções, de couro e calçados.

A adequação desse ordenamento aos dados brasileiros, especialmente sobre empregos, é direta em função da correspondência entre a Isic Revisão 3.1 e a Classificação Nacional de Atividades Econômicas (Cnae 1.0), disponibilizada pelo Ministério do Trabalho e Emprego (MTE). As atividades da Cnae de acordo com a metodologia da OCDE são apresentadas no quadro 1.

\section{Quadro 1 - Classificação das atividades industriais segundo metodologia da OCDE}

\begin{tabular}{|c|c|}
\hline $\begin{array}{l}\text { Intensidade } \\
\text { tecnológica }\end{array}$ & Atividade segundo a Cnae 1.0 \\
\hline Alta & Produtos farmoquímicos \\
\hline Alta & Medicamentos para uso humano \\
\hline Alta & Medicamentos para uso veterinário \\
\hline Alta & Materiais para usos médicos, hospitalares e odontológicos \\
\hline Alta & Máquinas para escritório e equipamentos de informática \\
\hline Alta & Material eletrônico e de aparelhos e equipamentos de comunicações \\
\hline Alta & Equipamentos de precisão \\
\hline Alta & Construção e montagem de aeronaves \\
\hline Alta & Reparação de aeronaves \\
\hline Baixa & Produtos alimentícios e bebidas \\
\hline Baixa & Produtos do fumo \\
\hline Baixa & Produtos têxteis \\
\hline Baixa & Confeç̧ão de artigos do vestuário e acessórios \\
\hline Baixa & Preparação de couros e fabricação de artefatos de couro \\
\hline Baixa & Produtos de madeira \\
\hline Baixa & Celulose, papel e produtos de papel \\
\hline Baixa & Edição, impressão e reprodução de gravações \\
\hline Baixa & Móveis e indústrias diversas \\
\hline Baixa & Reciclagem \\
\hline Média-alta & Produtos químicos \\
\hline Média-alta & Máquinas e equipamentos \\
\hline Média-alta & Máquinas, aparelhos e materiais elétricos \\
\hline Média-alta & Fabricação e montagem de veículos automotores, reboques e carrocerias \\
\hline Média-alta & Construção e montagem de locomotivas, vagões e outros materiais rodantes \\
\hline Média-alta & Fabricação de peças e acessórios para veículos ferroviários \\
\hline
\end{tabular}




\begin{tabular}{lc}
\hline $\begin{array}{l}\text { Intensidade } \\
\text { tecnológica }\end{array}$ & Atividade segundo a Cnae 1.0 \\
\hline $\begin{array}{l}\text { Média-alta } \\
\text { Média-alta }\end{array}$ & Reparação de veículos ferroviários \\
Média-alta & Motocicletas \\
Média-alta & Fabricação de bicicletas e triciclos não motorizados \\
Média-baixa & Fabricação de outros equipamentos de transporte \\
& Refino de petróleo, elaboração de combustíveis nucleares e produção de \\
Média-baixa & Fabricaçãa de artigos de borracha e plástico \\
Média-baixa & Fabricação de produtos de minerais não metálicos \\
Média-baixa & Metalurgia básica \\
Média-baixa & Fabricação de produtos de metal exceto máquinas e equipamentos \\
Média-baixa & Construção e reparação de embarcações e estruturas flutuantes \\
Média-baixa & Construção e reparação de embarcações para esporte e lazer \\
\hline Fonte: elaboração própria a partir de OCDE (2011) e IBGE (2013).
\end{tabular}

A partir dessa classificação, foi possível obter a quantidade de empregos na indústria de transformação de acordo com a intensidade tecnológica para a $\mathrm{MMC}^{1}$, demais mesorregiões do Paraná e do Brasil, nos anos de 2002 e 2011, conforme tabela 1 .

\begin{tabular}{lcccc}
\multicolumn{5}{c}{ Tabela 1 - Empregos da indústria da transformação segundo níveis de } \\
intensidade tecnológica - MMC e demais mesorregiões do Paraná e Brasil - \\
2002/2011 \\
$\begin{array}{lcccc}\text { Níveis de intensidade } \\
\text { tecnológica }\end{array}$ & $\begin{array}{c}\text { Mesorregião } \\
\text { Metropolitana } \\
\text { de Curitiba }\end{array}$ & $\begin{array}{c}\text { Demais } \\
\text { mesorregiões } \\
\text { do Paraná }\end{array}$ & $\begin{array}{c}\text { Demais } \\
\text { mesorregiões do } \\
\text { Brasil }\end{array}$ & $\begin{array}{c}\text { Total das } \\
\text { mesorregĩes } \\
\text { do Brasil }\end{array}$ \\
\hline 2002 & & & & \\
Alta & 5.606 & 2.578 & 199.088 & 207.272 \\
Baixa & 55.720 & 210.167 & 2.618 .463 & 2.884 .350 \\
Média-alta & 44.546 & 20.148 & 831.794 & 896.488 \\
Média-baixa & 31.691 & 35.647 & 1.075 .445 & 1.142 .783 \\
Total & 137.563 & 268.540 & 4.724 .790 & 5.130 .893 \\
2011 & & & & \\
Alta & 12.159 & 8.249 & 330.246 & 350.654 \\
Baixa & 73.607 & 325.027 & 3.637 .072 & 4.035 .706 \\
Média-alta & 83.789 & 52.518 & 1.564 .741 & 1.701 .048 \\
Média-baixa & 53.577 & 57.485 & 1.670 .104 & 1.781 .166 \\
Total & 223.132 & 443.279 & 7.202 .163 & 7.868 .574 \\
\hline
\end{tabular}

Fonte: elaboração própria a partir de BRASIL (2002; 2011), OCDE (2011) e IBGE (2013).

Por intermédio dessa distribuição são conhecidas as medidas, absoluta e relativa, de concentração industrial, assim como a similaridade da estrutura industrial entre a mesorregião em foco e seus pares, a concentração locacional das atividades e ainda o coeficiente de multiplicação de empregos naquelas

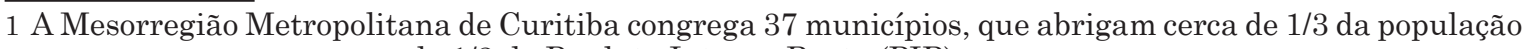
paranaense e geram cerca de $1 / 2$ do Produto Interno Bruto (PIB). 
atividades cujo quociente de localização excede a unidade.

\section{Desempenho da Indústria de Transformação na MMC}

A análise da estrutura econômica regional é crucial tanto para o diagnóstico, quanto para o processo de formulação de políticas territoriais (Boisier, 1997). Para conhecer a dinâmica da indústria de transformação da MMC será calculado um conjunto de indicadores de desempenho tendo em vista a intensidade tecnológica empregada.

De saída, haverá a verificação do crescimento dos empregos na mesorregião, para entãoanalisaraparticipaçãodelanaindústria detransformação nacional. Em seguida, será identificada a restruturação da mesorregião ao longo do tempo, sua especialização e, por fim, o efeito multiplicador que essa especialização propicia em termos de emprego na indústria de transformação.

\subsection{Crescimento}

O primeiro índice representa a porcentagem da região $j$ dentro da atividade do setor $i$ e pode ser utilizado para observar a distribuição interregional do setor ou a concentração absoluta (Boisier, 1980). Esse índice é calculado da seguinte forma:

$$
P_{i j}=\frac{V_{i j}}{\sum_{i} V_{i j}}
$$

sendo $V=$ variável estudada (emprego), $i=$ setor e $j=$ região.

Tabela 2 - Participação relativa dos empregos da indústria da transformação segundo níveis de intensidade tecnológica - MMC e demais mesorregiões do Paraná e do Brasil - 2002/2011

\begin{tabular}{lccc}
\hline $\begin{array}{l}\text { Níveis de } \\
\text { intensidade } \\
\text { tecnológica }\end{array}$ & $\begin{array}{c}\text { Mesorregião } \\
\text { Metropolitana de } \\
\text { Curitiba }\end{array}$ & $\begin{array}{c}\text { Demais } \\
\text { mesorregiões do } \\
\text { Paraná }\end{array}$ & $\begin{array}{c}\text { Demais } \\
\text { mesorregiões } \\
\text { do Brasil }\end{array}$ \\
\hline 2002 & & & \\
Alta & 2,705 & 1,244 & 96,052 \\
Baixa & 1,932 & 7,286 & 90,782 \\
Média-alta & 4,969 & 2,247 & 92,784 \\
Média-baixa & 2,773 & 3,119 & 94,108 \\
Total & 2,681 & 5,234 & 92,085 \\
2011 & & & \\
Alta & 3,468 & 2,352 & 94,180 \\
Baixa & 1,824 & 8,054 & 90,122 \\
Média-alta & 4,926 & 3,087 & 91,987 \\
Média-baixa & 3,008 & 3,227 & 93,765 \\
Total & 2,836 & 5,634 & 91,531 \\
\hline Fina
\end{tabular}

Fonte: elaboração própria a partir de BRASIL (2002; 2011), OCDE (2011) e IBGE (2013). 
Percebe-se que a MMC respondia por aproximadamente 2,7\% dos empregos em atividades de alta tecnologia em 2002. Em 2011, já abarcava $3,46 \%$ em postos de trabalho nesse mesmo universo.

Adiante, haverá a apresentação de algumas informações sobre a dinâmica do emprego na indústria de transformação na MMC. O cálculo dos índices de crescimento das oportunidades laborais será feito com as seguintes fórmulas:

- Variação regional:

$$
r R_{j}=\frac{\sum_{i} V_{i j}(t)}{\sum_{i} V_{i j}(0)}
$$

- Variação do setor na região:

$$
V_{i j}=\frac{V_{i j}(t)}{V_{i j}(0)}
$$

- Variação do setor em relação ao país:

$$
r S_{i}=\frac{\sum_{j} V_{i j}(t)}{\sum_{j} V_{i j}(0)}
$$

- Variação global em relação ao país:

$$
r S R=\frac{\sum_{i} \sum_{j} V_{i j}(t)}{\sum_{i} \sum_{j} V_{i j}(0)}
$$

Considerados esses indicadores, a MMC apresentou crescimento $(r R j)$ de $62 \%$ no volume de empregos na indústria de transformação entre 2002 e 2011, enquanto que o mesmo avanço esteve em $53 \%$ para o país $(r S R)$. As atividades de alta tecnologia foram as que mais evoluíram na MMC, em $117 \%$, ao passo que no Brasil expandiram-se em (RSi) 69\%, segundo dados da tabela 3.

Percebe-se que a MMC avançou $88 \%$ nas atividades de média-alta tecnologia, ligeiramente menos que o percentual nacional, cuja evolução foi de 90\%. Nas atividades de baixa tecnologia, as taxas de crescimento alcançaram, respectivamente, $32 \%$ e $40 \% \%$. O maior impulso nas atividades de alta tecnologia sinaliza que a MMC começa concentrá-las relativamente mais que o restante do país. 
Tabela 3 - Taxa de crescimento do emprego, em (\%), da indústria de transformação segundo níveis de intensidade tecnológica - MMC e demais mesorregiões do Paraná e Brasil - 2002/2011

\begin{tabular}{lcccc}
\hline $\begin{array}{l}\text { Níveis de intensidade } \\
\text { tecnológica }\end{array}$ & $\begin{array}{c}\text { Mesorregião } \\
\text { Metropolitana } \\
\text { de Curitiba }\end{array}$ & $\begin{array}{c}\text { Demais } \\
\text { Mesorregiões } \\
\text { do Paraná }\end{array}$ & $\begin{array}{c}\text { Demais } \\
\text { mesorregiões } \\
\text { do Brasil }\end{array}$ & $\begin{array}{c}\text { Crescimento do } \\
\text { setor em âmbito } \\
\text { nacional }\end{array}$ \\
\hline Alta & 116,89 & 219,98 & 65,88 & 69,18 \\
Baixa & 32,10 & 54,65 & 38,90 & 39,92 \\
Média-alta & 88,10 & 160,66 & 88,12 & 89,75 \\
Média-baixa & 69,06 & 61,26 & 55,29 & 55,86 \\
Crescimento 2002/2011 & 62,20 & 65,07 & 52,43 & 53,36 \\
\hline
\end{tabular}

Fonte: elaboração própria a partir de BRASIL (2002; 2011), OCDE (2011) e IBGE (2013).

\subsection{Participação}

No cálculo sobre a participação das atividades (Pij) na região e no âmbito nacional utilizou-se a seguinte fórmula:

$$
P_{i j}=100 *\left(V_{i j} / \sum_{i} V_{i j}\right)
$$

O resultado representa a participação da atividade $i$ (classificada de acordo com intensidades tecnológica) na região $j$ e pode, portanto, ser utilizado para observar a distribuição inter-regional e intra-regional do setor ou a concentração absoluta (Boisier, 1980).

$\mathrm{O}$ indicador revela que a MMC apresentava mais empregos nas atividades da indústria de transformação associadas à baixa tecnologia 40,51\% em 2002 e 32,99\% em 2011. Contudo, para o país, essas porcentagens eram, respectivamente, de 55,42\% e 50,50\% e, para as demais mesorregiões do Paraná, de 78,26\% e 73,32\%\%. Portanto, a MMC concentrava relativamente menos postos nas atividades de baixa tecnologia em relação aos percentuais relativos das demais mesorregiões.

Adicionalmente, a MMC passa a concentrar relativamente mais empregos em atividades de maior conteúdo tecnológico em 2011. Estas representavam, em 2002, 4,08\% dos empregos nesse contexto e 4,21\% para as demais mesorregiões do Brasil. No ano de 2011, chegam a 4,59\% para o país e $5,45 \%$ para a mesorregião, conforme exposto na tabela 4 .

$\mathrm{O}$ crescimento dessas atividades na MMC deve-se à expansão de $117 \%$ no conjunto de alta tecnologia, com destaque às seguintes: (i) fabricação de materiais para usos médicos, hospitalares e odontológicos - impulso de 511\%; (ii) fabricação de máquinas para escritórios e equipamentos - avanço de 371,5\%; (iii) reparação de aeronaves - aumento de 439,3\%. Há ainda o início da atividade de construção e montagem de aeronaves. No ano de 2002, não existia registro de empregos a ela associados, mas em 2011 já apareciam 96 trabalhadores contabilizados. 
Os resultados sugerem que a MMC passa a contratar, em 2011, relativamente mais nas atividades com maior intensidade tecnológica, em comparação à participação média de empregos nessas atividades nas demais mesorregiões do país. Ou seja, começa a reestruturar-se no sentido de concentrar atividades de maior intensidade tecnológica no período 2002-2011.

Tabela 4 - Participação nos níveis de intensidade tecnológica - MMC e demais mesorregiões do Paraná e do Brasil - 2002/2011

\begin{tabular}{lccc}
\hline $\begin{array}{l}\text { Níveis de intensidade } \\
\text { tecnológica }\end{array}$ & $\begin{array}{c}\text { Mesorregião } \\
\text { Metropolitana de } \\
\text { Curitiba }\end{array}$ & $\begin{array}{c}\text { Média das demais } \\
\text { mesorregióes do } \\
\text { Paraná }\end{array}$ & $\begin{array}{c}\text { Média das demais } \\
\text { mesorregiões do } \\
\text { Brasil }\end{array}$ \\
\hline 2002 & 4,08 & & \\
Alta & 40,51 & 0,96 & 4,21 \\
Baixa & 32,38 & 78,26 & 55,42 \\
Média-alta & 23,04 & 7,50 & 17,60 \\
Média-baixa & & 13,27 & 22,76 \\
2011 & 5,45 & & 4,59 \\
Alta & 32,99 & 1,86 & 50,50 \\
Baixa & 37,55 & 73,32 & 21,73 \\
Média-alta & 24,01 & 11,85 & 23,19 \\
Média-baixa & 12,97 & \\
\hline
\end{tabular}

Fonte: elaboração própria a partir de BRASIL (2002; 2011), OCDE (2011) e IBGE (2013).

\subsection{Reestruturação}

Para mensurar a reestruturação utilizou-se o coeficiente que compara a estrutura regional, em termos de composição das atividades, nos momentos inicial (0) e final (t), conforme a fórmula abaixo:

$$
C R_{r}=\left(\frac{1}{2}\right) * \sum_{i}\left\{A B S\left[\frac{V_{i j}(t)}{\sum_{i} V_{i j}(t)}-\frac{V_{i j}(0)}{\sum_{i} V_{i j}(0)}\right]\right\} 2
$$

Esse índice varia entre 0 e 1 . Caso o coeficiente esteja próximo a 0 , aponta que não ocorreu alteração na estrutura econômica; se o coeficiente for igual a 1 indica que ocorreu significativa mudança .

O coeficiente de reestruturação para a MMC foi de 0,07515, como apresentado na tabela 5, o que assinala uma reestruturação discreta entre 2002 e 2011. Há um ligeiro redirecionamento para o aumento da participação das atividades de alta, média-alta e média-baixa tecnologia, com redução daquelas de baixa tecnologia, o que sinaliza avanço da especialização em setores de intensidade tecnológica maior.

2 ABS é um número com valor absoluto 
Tabela 5 - Coeficiente de reestruturação segundo níveis de intensidade tecnológica - MMC e demais mesorregiões do Paraná e do Brasil - 2011

\begin{tabular}{lccc}
\hline $\begin{array}{l}\text { Níveis de intensidade } \\
\text { tecnológica }\end{array}$ & $\begin{array}{c}\text { Mesorregião } \\
\text { Metropolitana de } \\
\text { Curitiba }\end{array}$ & $\begin{array}{c}\text { Demais mesorregiões } \\
\text { do Paraná }\end{array}$ & $\begin{array}{c}\text { Demais mesorregiões } \\
\text { do Brasil }\end{array}$ \\
\hline Alta & 0,0137 & 0,009 & 0,0037 \\
Baixa & $-0,0752$ & $-0,0494$ & $-0,0492$ \\
Média-alta & 0,0517 & 0,0434 & 0,0412 \\
Média-baixa & 0,0097 & $-0,0031$ & 0,0043 \\
Total & 0,07515 & 0,05245 & 0,0492 \\
\hline
\end{tabular}

Fonte: elaboração própria a partir de BRASIL (2011), OCDE (2011) e IBGE (2013).

Para identificar o grau de especialização em determinadas atividades houve o emprego do Quociente Locacional (QL). Esse índice é calculado pela seguinte fórmula:

$$
Q L=\frac{\frac{V_{i j}}{\sum_{i} V_{i j}}}{\frac{\sum_{j} V_{i j}}{\sum_{i} \sum_{j} V_{i j}}}
$$

Caso o quociente exceda a unidade $Q L>1$, aponta que as atividades têm um peso relativo maior na região que no país, ou seja, a região especializou-se nas atividades de índice maior que a unidade.

Percebe-se que a MMC apresentava ligeira concentração nas atividades de alta, média-baixa e média-alta tecnologia em 2002. Em 2011, acentua-se o quociente de localização em atividades de alta tecnologia, contudo, diminui ligeiramente em média-alta.

Tabela 6 - Quociente de localização segundo níveis de intensidade tecnológica - MMC e demais mesorregiões do Paraná e do Brasil - 2002/2011

\begin{tabular}{lccc}
\hline $\begin{array}{l}\text { Níveis de intensidade } \\
\text { tecnológica }\end{array}$ & $\begin{array}{c}\text { Mesorregião } \\
\text { Metropolitana de } \\
\text { Curitiba }\end{array}$ & $\begin{array}{c}\text { Demais mesorregiões } \\
\text { do Paraná }\end{array}$ & $\begin{array}{c}\text { Demais mesorregiões } \\
\text { do Brasil }\end{array}$ \\
\hline 2002 & 1,01 & 0,24 & 1,04 \\
Alta & 0,72 & 1,39 & 0,99 \\
Baixa & 1,85 & 0,43 & 1,01 \\
Média-alta & 1,03 & 0,60 & 1,02 \\
Média-baixa & & & \\
2011 & 1,22 & 0,42 & 1,03 \\
Alta & 0,64 & 1,43 & 0,98 \\
Baixa & 1,74 & 0,55 & 1,01 \\
Média-alta & 1,06 & 0,57 & 1,02 \\
Média-baixa & Fonte: elaboração própria a partir de BRASIL (2002; 2011), OCDE (2011) e IBGE (2013).
\end{tabular}


Além de deter maior domínio em atividades de alta e de média-alta tecnologia, a MMC é mais diversificada que as demais mesorregiões paranaenses, as quais se especializaram em atividades de baixa tecnologia, como indicam os Quocientes de Localização delas na tabela 6: 1,39 em 2002 e 1,43 em 2011.

Tal constatação é também apontada pelo Coeficiente de Especialização $(\mathrm{Qr})$, calculado pela seguinte equação:

$$
Q_{r}=\frac{1}{2} * \sum_{i}\left\{A B S\left[\left(\frac{V_{i j}}{\sum_{i} V_{i j}}\right)-\left(\frac{\sum_{j} V_{i j}}{\sum_{i} \sum_{j} V_{i j}}\right)\right]\right\}
$$

Esse índice traduz a concentração relativa das atividades na região por meio da comparação da participação dela em relação ao total de atividades, considerado o peso relativo no âmbito nacional. Quanto mais próximo de zero, maior diversificação possui a estrutura produtiva regional, ou seja, há mais similaridade com a estrutura produtiva do país. Por outro lado, quanto mais próximo de 1, maior é a concentração.

Na comparação entre o modelo industrial da MMC e aqueles das demais mesorregiões paranaenses, percebe-se que este primeiro assemelha-se ao nacional. Conclui-se isso pela proximidade do coeficiente de especialização da mesorregião a zero, em ambos os anos avaliados, conforme aponta a tabela 7 .

Tabela 7 - Quociente de especialização segundo níveis de intensidade tecnológica - MMC e demais mesorregiões do Paraná e do Brasil - 2002/2011

\begin{tabular}{lccc}
\hline $\begin{array}{l}\text { Níveis de intensidade } \\
\text { tecnológica }\end{array}$ & $\begin{array}{c}\text { Mesorregião } \\
\text { Metropolitana de } \\
\text { Curitiba }\end{array}$ & $\begin{array}{c}\text { Demais mesorregiões } \\
\text { do Paraná }\end{array}$ & $\begin{array}{c}\text { Demais mesorregiões } \\
\text { do Brasil }\end{array}$ \\
\hline 2002 & 0,0004 & $-0,0308$ & 0,0017 \\
Alta & $-0,1571$ & 0,2205 & $-0,008$ \\
Baixa & 0,1491 & $-0,0997$ & 0,0013 \\
Média-alta & 0,0076 & $-0,09$ & 0,0049 \\
Média-baixa & 0,1571 & 0,2205 & 0,0079 \\
Total & & & \\
2011 & 0,0099 & $-0,026$ & 0,0013 \\
Alta & $-0,183$ & 0,2203 & $-0,0079$ \\
Baixa & 0,1593 & $-0,0977$ & 0,0011 \\
Média-alta & 0,0137 & $-0,0967$ & 0,0055 \\
Média-baixa & 0,1829 & 0,2203 & 0,0079 \\
Total & & & \\
\hline
\end{tabular}

Fonte: elaboração própria a partir de BRASIL (2002; 2011), OCDE (2011) e IBGE (2013).

\subsection{Competitividade e efeito multiplicador}

Os índices desta seção demostram o comportamento intertemporal das regiões e indicam eventuais fatores de competitividades por meio de (Xij) e do 
multiplicador (Mj), apresentados abaixo, conforme Lira e Quiroga (2003):

$$
X_{i j}=V_{i j}-\left(\frac{V_{i j}}{Q L_{i j}}\right), \text { para todos os } Q L_{i j}>1
$$

Expressão que equivale a:

$$
\begin{gathered}
X_{i j}=V_{i j}-\left\{\frac{V_{i j}}{\left[\frac{V_{i j}}{\frac{\sum_{i} V_{i j}}{\sum_{j} V_{i j}}}\right]}\right] \text {, para todos os } Q L_{i j}>1 \\
X_{i j} V_{i j}=\sum_{i} X_{i j} P B_{j}
\end{gathered}
$$

Sendo a produção básica $\mathrm{PB}$ (ou exportável) do setor $i$ da região $j$ que possui o $Q L i j>1$ (evidência de especialização). Nesse caso, a quantidade de emprego excederia mais que proporcionalmente o tamanho da região, ou seja, a área emprega mais do que necessita para atender à demanda interna ${ }^{3} . \mathrm{Na}$ equação (10), a fração expressa o consumo interno. Logo, representa a produção exportável da região $j$, sendo, portanto, um eventual fator de competitividade (Malecki 1997).

$$
P T=P B_{j}+P N B_{j}
$$

Sendo: $P T=$ produção total; $P B j=$ produção básica da região $j ; P N B j=$ produção não básica da região $j$.

$$
M_{j}=1+p_{j}=P T / P B_{j}
$$

O Mj refere-se ao multiplicador básico regional, o diz respeito à produção total e corresponde ao coeficiente de base ou à relação entre a produção não básica e básica . Essa constatação matemática sugere eventual encadeamento de atividades, cujo exame requereria técnicas adicionais como insumo-produto (Haddad, 1989; Isard, 1971; Richardson, 1986). As análises tradicionais de economia regional atribuem esse peso relativo maior às atividades de exportação, assinalado por Aguilera e Modesta (2001), assim como por Bonet (2000).

Portanto, consideradas as especializações daMMC, essa mesorregião seria exportadora de produtos/serviços de atividades associadas à alta, à média-alta $\mathrm{e}$ à média-baixa tecnologia. Além disso, o cálculo apresenta os multiplicadores de empregos para cada trabalhador vinculado àquelas atividades. A interpretação do coeficiente $M i$ (multiplicador) é feita da seguinte forma: no ano de 2002,

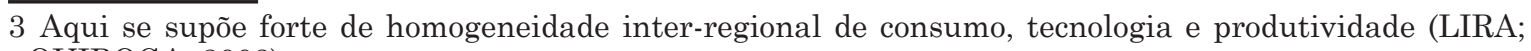
QUIROGA, 2003). 
para cada emprego gerado nas atividades nas quais a região era especializada $(Q L>1)$, houve o surgimento de seis adicionais, segundo a Tabela 8. Para o ano de 2011, eram cinco novos para cada emprego gerado nas mesmas atividades.

Tabela 8 - Multiplicador de empregos segundo níveis de intensidade tecnológica - MMC e demais mesorregiões do Paraná e do Brasil - 2002/2011

\begin{tabular}{|c|c|c|c|}
\hline $\begin{array}{l}\text { Níveis de intensidade } \\
\text { tecnológica }\end{array}$ & $\begin{array}{c}\text { Mesorregião } \\
\text { Metropolitana de } \\
\text { Curitiba }\end{array}$ & $\begin{array}{c}\text { Demais mesorregiões } \\
\text { do Paraná }\end{array}$ & $\begin{array}{c}\text { Demais mesorregiões } \\
\text { do Brasil }\end{array}$ \\
\hline \multicolumn{4}{|l|}{2002} \\
\hline Alta & 49 & 0 & 8226 \\
\hline Baixa & 0 & 59207 & 0 \\
\hline Média-alta & 20510 & 0 & 6274 \\
\hline Média-baixa & 1051 & 0 & 23150 \\
\hline $\mathrm{Xj}=\mathrm{PBj}$ & 21610 & 59207 & 37651 \\
\hline TOTAL REGIONAL & 137563 & 268540 & 4724790 \\
\hline $\mathrm{Mj}$ & 6 & 5 & 125 \\
\hline \multicolumn{4}{|l|}{2011} \\
\hline Alta & 2215 & 0 & 9276 \\
\hline Baixa & 0 & 97672 & 0 \\
\hline Média-alta & 35551 & 0 & 7785 \\
\hline Média-baixa & 3066 & 0 & 39780 \\
\hline $\mathrm{Xj}=\mathrm{PBj}$ & 40833 & 97672 & 56841 \\
\hline TOTAL REGIONAL & 223132 & 443279 & 7202163 \\
\hline $\mathrm{Mj}$ & 5 & 5 & 127 \\
\hline
\end{tabular}

Fonte: elaboração própria a partir de BRASIL (2002; 2011), OCDE (2011) e IBGE (2013).

\section{Conclusão}

O objetivo do trabalho foi verificar o desempenho da indústria da transformação na MMC. Para tanto, houve a classificação das atividades do setor de acordo com a intensidade tecnológica com base na metodologia proposta pela OCDE. O recorte geográfico incluiu todas as mesorregiões paranaenses, porém, com especial enfoque à MMC. Esta última obteve crescimento mais acelerado que as demais no estado em atividades associadas à indústria de intensidade tecnológica elevada, o que sinaliza uma concentração.

A MMC ainda possui uma estrutura econômica mais diversificada, se comparada a seus pares estaduais. Isso porque estas mantiveram especialização em atividades de baixa tecnologia, conforme apontam os quocientes locacionais, enquanto aquela passa a concentrar relativamente mais atividades de maior intensidade tecnológica.

Considerado o fato de que a MMC é exportadora de produtos e serviços de atividades tecnologicamente mais intensivas, calcularam-se os multiplicadores de empregos associados. No ano 2002, eram gerados cerca de seis postos de trabalho adicionais para cada um criado em uma das atividades 
de alta, de média-alta e de média-baixa tecnologia. No ano 2011, surgiam cinco oportunidades laborais para cada nova estabelecida. Levando em conta que as principais inovações ocorrem, usualmente, nas atividades de intensidade tecnológica mais elevada, os resultados sugerem um cenário favorável à MMC em relação à estrutura da indústria de transformação nacional. Assim, as informações apresentadas, além de revelarem que essa mesorregião começa a concentrar atividades de maior intensidade tecnológica, podem servir como subsídios aos planos de desenvolvimento local, em particular nas atividades de mais elevada tecnologia.

\section{Referências}

Aguilera, D.; Modesta, M. (2001). Comercio de Colombia con el Caribe insular 19901999. Centro de Estudios Económicos Regionales, Documento de trabajo nº 21. Cartagena de Indias: Banco de la República.

Bonet, M. J. (2000). Las exportaciones colombianas de banano, 1950-1998. Centro de Estudios Económicos Regionales, Documento de trabajo ${ }^{\circ}{ }^{\circ} 14$. Cartagena de Indias: Banco de la República.

Boisier, S. (1980). Técnicas de Análisis Regional con Información Limitada. Cuaderno ILPES, Serie II, n 27. Santiago de Chile: ILPES.

. (1997). El vuelo de una cometa: una metáfora para una teoría deldesarrollo territorial. Documento 37. Santiago de Chile: ILPES.

Brasil. Ministério do Trabalho e Emprego. (2002). "Relação Anual de Informações Sociais”. Brasília. Disponível em: <http://bi.mte.gov.br/bgproger/login.php>. Acesso em: 24 Jul. 2013.

. Ministério do Trabalho e Emprego. (2011). "Relação Anual de Informações Sociais”. Brasília. Disponível em: <http://bi.mte.gov.br/bgproger/login.php>. Acesso em: 24 Jul. 2013.

Furtado, A. T.; Carvalho, R. De Q. (2005). "Padrões de intensidade tecnológica da indústria brasileira: um estudo comparativo com os países centrais”. São Paulo em Perspectiva, São Paulo, v.19, n. 1, jan./mar., p. 70-84.

Haddad, P. (1989). Economia Regional: teorias e métodos de análise. Fortaleza: Banco do Nordeste do Brasil S.A.

IBGE - Instituto Brasileiro De Geografia E Estatística. (2013). "Classificação Nacional de Atividades Econômicas, versão 1.0”. Rio de Janeiro. Disponível em: <http://www.cnae.ibge.gov.br/estrutura.asp>. Acesso em: 19 Ago. 2013.

Isard, W. (1971). Métodos de Análisis Regional: una introducción a la Ciencia Regional. Barcelona: Ediciones Aries.

Lira, L.; Quiroga, B. (2003). Técnicas de análisis regional. Santiago de Chile: Instituto Latinoamericano y del Caribe de Planificación Económica y Social (ILPES).

Malecki, E. J. (1997). Technology and economic development: the dynamics of local, regional, and national change. Nova Iorque: Longman.

Markwald, R. (2004). "Intensidade tecnológica e dinamismo das exportações 
brasileiras". Revista Brasileira de Comércio Exterior, Rio de Janeiro, n. 79, p.3-11 OCDE - Organização Para A Cooperação E Desenvolvimento Econômico. (2011). International Standard Industrial Classification of all Economic Activities (Isic), Rev.3.1, Technology Intensity Definition. Paris. Disponível em: <http://unstats. un.org/unsd/publication/seriesM/seriesm_4rev4e.pdf>. Acesso em: 1 Jul. 2013.

Richardson, H. (1986). Economía Regional y Urbana. Madrid: Alianza Editorial. 